\title{
Trabalhonecessário
}

Issn: $1808-799 X$

ano 13, número $21-2015$

\section{DO TRABALHO SOCIALMENTE NECESSÁRIO AO POLITECNISMO A PARTIR DE VIKTOR SHULGIN: FUNDAMENTOS DE UMA EXPERIÊNCIA EDUCATIVA REVOLUCIONÁRIA}

\author{
Leonardo Dorneles Gonçalves ${ }^{1}$ \\ Conceição Paludo²
}

\section{Resumo}

O presente artigo busca adentrar no entendimento da relação trabalho/educação, tendo como referência básica a experiência russa ocorrida no início do século 20 . O autor que serve de referência para o estudo é Viktor Shulgin, por ter sido quem se debruçou sobre o conceito de politecnismo, também referido pelo termo politecnia. $\mathrm{O}$ artigo caracteriza-se como uma pesquisa bibliográfica. Ao final, o estudo mostra que, para o autor, o trabalho é o aspecto dinamizador, tanto da forma como do conteúdo escolar. Exatamente por esse entendimento, no contexto da Rússia do início do século 20, Shulgin transita do conceito de Trabalho Socialmente Necessário para o de Politecnismo, o que se colocava como necessidade naquele momento histórico.

\footnotetext{
${ }^{1}$ Pedagogo. Mestre pelo Programa de Pós-Graduação em Educação Ambiental da Universidade Federal do Rio Grande (FURG). Doutorando em Educação no Programa de Pós-Graduação em Educação da Universidade Federal de Pelotas (UFPel), com pesquisas no campo do Trabalho e Educação, especificamente as políticas públicas educativas no âmbito do Ensino Médio. Email: $<$ dorneles05@gmail.com>.

2 Professora Adjunta na Universidade Federal do Rio Grande do Sul (UFRGS). Mestre e doutora em Educação no Programa de Pós-Graduação em Educação da Universidade Federal do Rio Grande do Sul (UFRGS). Coordena pesquisas ligadas aos temas da Educação do Campo, Educação e Trabalho, Educação Popular, Movimentos Sociais Populares e Escola Pública. Email: <c.paludo@terra.com>.
}

TrabalhoNecessário - www.uff.br/trabalhonecessario; Ano 13, № 21/2015. 


\title{
Trabalhonecessário
}

Issn: $1808-799 X$

ano 13, número $21-2015$

Palavras-chave: Trabalho; Educação; Politecnismo.

\begin{abstract}
This article seeks to understand the relationship between work and education, having as basic reference the Russian experience that took place at the beginning of the 20th century. The referential author of this study is Viktor Shulgin, for being the author who addressed the concept of polytechnics. The article characterizes itself as a literature search. In the end, the present paper shows that, for the author, the work is the dynamic aspect of both the school form and the content. Just because of this understanding in the context of the early 20th century Russia, Shulgin moves from the concept of Socially Necessary Labor to the concept of Polytechnics, which was placed as a necessity in that historic moment.
\end{abstract}

Keywords: Work; Education; Polytechnics.

No século 19, Marx e Engels firmam a produção da vida pelo trabalho como fundante do ser social e da realidade social. A partir deles, a relação trabalho/educação passa a ser estudada e debatida por inúmeros teóricos, os quais contribuem com estudos específicos, reflexos de específicos momentos históricos, estendendo-se até a atualidade.

Nessa pesquisa bibliográfica, interessou a formulação e a prática da relação existente entre trabalho e educação na experiência ocorrida na Rússia, no período que corresponde a 1917 até meados de 1931, quando se alteram substantivamente a orientação e as práticas políticas do governo russo, sob o comando de J. Stalin. 


\section{Trabalhonecessário}

Issn: $1808-799 X$

ano 13, número $21-2015$

O objetivo do estudo é adentrar na compreensão do trabalho como princípio educativo, vivenciado e posteriormente teorizado por educadores/pedagogos russos, sobretudo Moisey Pistrak, Anton Makarenko e Viktor Shulgin. Entretanto, o autor selecionado neste texto é Viktor Shulgin, precisamente por ter sido o que mais se debruçou sobre essa reflexão, chegando ao conceito de politecnismo. Como resultado do estudo, apresenta-se, num primeiro momento, o contexto no qual Shulgin viveu e formulou as suas reflexões, Em seguida, apresenta-se a sua compreensão de Trabalho Socialmente Necessário e do papel da escola para, posteriormente, ser situada a transição da formulação do conceito de Trabalho Socialmente Necessário para o de politecnismo. Finalmente, são tecidas algumas conclusões.

\section{Elementos contextuais do processo revolucionário}

Tomando por base os estudos de Reis Filho (1989), Tragtenberg (2007), Moreno (2003), pode-se dizer que o processo histórico que acarretou na formação social russa é complexo e contraditório, se comparado a outros países da Europa nos primeiros anos do século 20. Como é sabido, o capitalismo não se desenvolveu plenamente nos países fora do eixo ocidental (Europa e Estados Unidos), mas a partir de uma combinação de distintos regimes de acumulação, caracterizando, no caso da Rússia, um país de contrastes, onde conviviam realidades agrárias e industriais, população ilustrada e analfabeta, uma mescla populacional europeia e asiática, tendo a maioria dos habitantes vivendo no campo e responsável pela exportação de grãos para a Europa. Nesse aspecto, as condições de vida da maioria do povo, no início do século 20, sequer tinha alcançado os níveis dos direitos europeus, devido à frágil e dispersa organização dos trabalhadores altamente explorados nas indústrias e no trabalho rural. Esse 


\section{Trabalhonecessário}

Issn: $1808-799 X$

ano 13, número $21-2015$

último contava, por exemplo, na maioria das propriedades, com uma estrutura semifeudal, seja pelas técnicas utilizadas, seja através das relações de trabalho.

Além de ser um país com profundas desigualdades sociais, a Rússia do início do referido século era governada por um imperador - czar - e sua forma política era uma autocracia. As liberdades, as organizações de classe, jornais opositores e greves eram proibidos, sob pena do exílio para execução de trabalhos forçados, exceto aqueles que conseguiam escapar e se estabeleciam em países onde a classe operária obtinha certa tradição organizativa. (REIS FILHO, 1989). Todo o poder concentrado no czar permitia a realização de uma política opressora, o que agudizava a fome entre o povo pobre do campo e das poucas cidades industriais que existiam, o que justificava o ódio que o povo russo nutria pelo czarismo e o desejo pelo fim deste regime como condição de defesa da pátria. (FERRO, 1967).

Dessa forma, o país empilhou diversos conflitos, desde os primeiros anos do século, quando enfrentou o Japão em disputa por territórios asiáticos, entre eles o da Coreia. A guerra foi perdida, aumentando os problemas como a fome, revoltas, sofrimentos e gerando a primeira crise da autocracia do império russo, endereçada em contrariedade ao czar, denominada como "Ensaio Geral"3. As consequências da chacina russa resultaram em revoltas populares, greves operárias e lutas por liberdades democráticas e na constituição de um parlamento, que, no limite, serviu como estratégia para o czar ganhar tempo e retomar o poder. Apesar disso, o levante popular obteve um ganho que seria fundamental para a Revolução Russa. O processo de organização do movimento reivindicatório contou com uma formação de conselhos e assembleias, cuja

\footnotetext{
${ }^{3}$ Em 1905, a população pobre, liderada por um padre da Igreja Ortodoxa, dirigiu-se ao czar por meio de uma carta, expondo-Ihe suas dificuldades e pedindo providências. A resposta foi dada com violência, quando a polícia do czar simplesmente assassinou as pessoas presentes. Sobre isso, ver Reis Filho (1989).
}

TrabalhoNecessário - www.uff.br/trabalhonecessario; Ano 13, № 21/2015. 


\section{Trabalhonecessário}

Issn: $1808-799 X$

ano 13, número $21-2015$

participação do povo era direta na construção de propostas. Denominados sovietes, esses conselhos

surgem como órgãos revolucionários que representam as classes proletárias urbanas ou rurais e sua estrutura organizatória toma a direção de uma democracia direta, tendo em vista atingir seu objetivo: a transformação estrutural da sociedade. (TRAGTENBERG, 2007, p. 109).

A formação e organização dos sovietes cumpriu um papel muito importante no processo revolucionário, uma vez que a sua existência se baseava no autogoverno, sem a intervenção de qualquer autoridade externa, superior e opressora. A existência e o fortalecimento dos sovietes como força revolucionária e as consequências de revoltas internas, a forte repressão autocrática, a guerra russo-japonesa e a adesão da Rússia na Primeira Guerra agudizaram aos extremos os problemas sociais, criando as condições para a Revolução de 1917.

Segundo Reis Filho (1989, p. 39),

"desde 1915, começaram a faltar gêneros essenciais. A indústria, concentrada em atender as necessidades do exército, não produzia bens de consumo corrente. Entre 1913 e 1916 o preço do pão subiria $63 \%$ nas regiões industrializadas".

Um país devastado por conflitos internos e externos, convivendo com condições insalubres manifestou-se contra o poder czarista. Os mencheviques, a corrente burguesa do Partido Operário Social-Democrata da Rússia, assumiram o controle do Estado e operaram as mudanças concernentes à implantação de um regime de liberdades, mas, por outro lado, mantiveram o país na Primeira Guerra, ignorando a necessidade da assinatura do tratado de paz. Somente em outubro de 1917, após o fracasso da política burguesa do governo provisório, os bolcheviques, liderados por Lenin e tendo sua base formada pelos sovietes, assumiram o controle da Rússia, dando origem a um "Estado operário, apoiado 


\section{Trabalhonecessário}

Issn: $1808-799 X$

ano 13, número $21-2015$

por camponeses e soldados. Não é uma revolução somente política, como a de fevereiro, mas uma revolução social". (MORENO, 2003 p. 49).

Nesta brevíssima retomada de parte da história da Revolução Russa, é preciso destacar a existência da chamada guerra civil, ocorrida nos anos posteriores à Revolução. Ao exército bolchevique era atribuída uma tripla tarefa: além de implantar um regime socialista no país, tinha que lutar contra os opositores da Revolução de outubro no espectro interno (o chamado exército branco) e o avanço das nações imperialistas que lutavam contra si na Primeira Guerra e que se viraram contra a Rússia após a Revolução. Ao final da guerra civil (1922), a Rússia era um país literalmente destruído, apesar da "vitória" do Exército Vermelho.

Sem indústrias, sem produção, com um exército profundamente debilitado, o governo russo constituiu a Nova Política Econômica - NEP, permitindo a existência de pequenas empresas privadas, como oficinas, lojas e médias propriedades rurais, ainda que controladas pelo Estado. Grandes indústrias e extensivas faixas de terra utilizadas para agricultura permaneciam administradas pelo governo, como acontecera desde 1917. (TRAGTENBERG, 2007). Isso proporcionou que a economia russa tivesse um crescimento acelerado e lograsse, em pouquíssimo tempo, um lugar entre as maiores economias do mundo 4 .

Da mesma forma, o processo revolucionário apresentou implicações na organização do sistema educacional, com o objetivo de ampliar o acesso de todas as pessoas ao conhecimento escolar, a realização da escola unitária em contraposição ao modelo atrelado à divisão social do trabalho existente antes da

\footnotetext{
${ }^{4}$ No início da década de 1930, com a chegada de Josef Stalin ao governo soviético, os caminhos da Revolução assumem a forma de uma ditadura. A coletivização forçada da agricultura, o silenciamento de membros importantes do partido, o assassinato daqueles que criticavam ao modelo stalinista são exemplos da forma como o governo deu sequência ao regime comunista. $\mathrm{Na}$ área educacional, muitos educadores foram acusados de serem contra o socialismo e, por isso, foram eliminados, entre eles o próprio Moisey. M. Pistrak.
}

TrabalhoNecessário - www.uff.br/trabalhonecessario; Ano 13, № 21/2015. 


\title{
Trabalhonecessário
}

Issn: $1808-799 X$

ano 13, número $21-2015$

revolução e a introdução do trabalho produtivo como principio dinamizador das práticas educativas, constituindo a escola unitária do trabalho.

Nas palavras de Ciavatta (2014)

\begin{abstract}
Além disso, o Estado chamava a si uma série de medidas e responsabilidades que daria forma à nova sociedade e à educação em todos os seus níveis: assumiria as escolas privadas e confessionais, haveria a separação entre Estado e Igreja e entre Igreja e escola na qual era proibida a instrução religiosa; roupa, alimentos e material escolar para todas as crianças em sistema de educação mista, abolição de notas e exames e uniformes; supressão do latim nas escolas superiores, fim das distinções hierárquicas e igualdade de salários para os professores, proibição de castigos e de tarefas de casa e transformação de todas as escolas em escolas unitárias de trabalho. (p. 192).
\end{abstract}

\section{O Trabalho Socialmente Necessário}

É no contexto acima descrito que as experiências histórico-práticas que possuem o trabalho como princípio educativo foram desenvolvidas. Entre elas destacam-se as de dois importantes pedagogos russos, conhecidos por sua produção no campo educativo: Anton Makarenko (1888-1939) e Moisey Mikhaylovich Pistrak (1888-1940). Ambos participaram das principais transformações sociais ocorridas na Rússia e contribuíram teórica e praticamente, na formulação do papel e contribuição da educação, para a construção da nova Rússia, de novos homens e mulheres. Inegavelmente são autores importantíssimos para a compreensão da pedagogia russa. Entretanto, este texto toma como referência os textos de Shulgin $^{5}$ (2013), precisamente porque o

5 Viktor Nikholaevich Shulgin (1894-1965) "trabalhou com Moisey Pistrak na Escola-comuna
Experimental Demonstrativa do Comissariado do Povo para Educação em Moscou. Educador e
historiador, Shulgin terminou seus estudos na Universidade de Moscou em 1917. Foi Membro do
conselho de Deputados da cidade de Ryazan e do Comitê Executivo, foi comissário provincial das TrabalhoNecessário - www.uff.br/trabalhonecessario; Ano 13, № 21/2015. 


\section{Trabalhonecessário}

Issn: $1808-799 X$

ano 13, número $21-2015$

conceito de Politecnismo trabalhado pelo autor é o que aqui interessa imediatamente e, também, por haver, em certa medida, um diálogo com os outros dois autores, sobretudo com Pistrak. (FREITAS, 2013).

De acordo com Shulgin, o papel do Trabalho na reconstrução russa, principalmente o Trabalho com resultados concretos na vida das aldeias e comunidades $^{6}$ - uma atividade que conduzisse à melhoria das condições de vida da população e atendesse aos propósitos da Revolução na forma como foi projetada a partir de 1917 -, pode ser entendido como Trabalho Socialmente Necessário. Portanto, não se trata de qualquer trabalho, mas aquele que tivesse um sentido naquilo que deveria ser feito. $E$ o que precisava ser feito? $A$ reconstrução da Rússia, a elevação da qualidade de vida, a construção de homens e mulheres novos, a superação do modo de vida atrasado (em alguns casos o trabalho com características feudais), movido pela busca da atualidade. Atualidade é um conceito atribuído a Pistrak com a colaboração de Shulgin (FREITAS, 2013). Para Pistrak, o papel da escola é o de estudar a realidade atual, onde se vive, profundamente. Seu entendimento era o de que

a escola não deve estudar as ruínas do passado: não deve estudá-las e assim será feito, mas com a compreensão de que são apenas ruínas do passado e de que seu estudo iluminado à luz da luta travada contra o passado e da transformação da vida que deve levar à sua liquidação. (PISTRAK, 2005, p. 33).

\footnotetext{
finanças e Comissário Provincial da Educação em Ryazan em 1918. Entre 1918-1922 trabalhou no Comissariado do Povo para a Educação. De 1922-1931 foi diretor do Instituto de Métodos do Trabalho Escolar. Trabalhou na Seção Científica [...] do Conselho Estatal (GUS) entre 1921-1931, presidida por N.K. Krupskaya" (FREITAS, 2013 p. 7-8). Depois disso, retirou-se das atividades de ensino e se envolveu com a investigação histórica, sendo inclusive funcionário científico do Museu da Revolução em Moscou.

${ }^{6}$ Em linhas gerais, o autor denomina comunidade o contexto local de cada região em que as escolas se fazem presentes, enquanto que por sociedade ele encaminha o sentido mais amplo que se materializa na realidade do país, a Rússia, como um todo. Para fins deste texto, adotamos as terminologias do autor sem alteração de sentido, a fim de manter a fidelidade de sua intenção.
}

TrabalhoNecessário - www.uff.br/trabalhonecessario; Ano 13, № 21/2015. 


\section{Trabalhonecessário}

Issn: $1808-799 X$

ano 13, número $21-2015$

Nesse ponto, o Trabalho Socialmente Necessário era uma prática que precisava ser realizada por todas as organizações sociais engajadas na reconstrução do país, sobretudo aquelas que possuíam uma ligação com o governo e com o partido. Portanto, tarefa destinada, também, à escola.

Com efeito, uma vez que a escola exercia um papel de contribuição na reconstrução do país, sem perder o seu caráter específico, emergia um dos principais problemas que Shulgin buscou resolver, em sua obra, denominada Rumo ao Politecnismo ${ }^{7}$. Para o autor, alguns questionamentos eram fundantes: Como o trabalho deveria acontecer na escola? Qual deveria ser o papel da escola? Pode-se dizer: qual a relação entre trabalho e educação escolarizada?

Para o autor, o Trabalho é a "forma de introduzir crianças e jovens na vida laboral, ligá-las com a classe-construtora, aprender a lutar e construir" (p. 41). Neste sentido, com base na crítica ao que denominou "complexos sentados", que pode ser entendido como a forma dicotômica e dualista em que a escola ainda trabalhava, resquícios do modelo burguês, Shulgin entendia que o primeiro papel social da escola é a pesquisa (p. 48) sobre a realidade da qual faz parte, como mediação necessária para romper com o distanciamento idealista entre escola e sociedade, projetando a intervenção na vida real. O conhecimento da realidade aproximaria a escola dos problemas que necessitam de solução, em conjunto com outras organizações sociais, para que pudessem trabalhar juntas. Em decorrência da pesquisa realizada, a escola faria ações que contribuíssem para a dinâmica da vida social, inclusive a partir de trabalhos práticos ${ }^{8}$. Ou seja, o

\footnotetext{
7 Neste artigo, consideramos o conceito de Politecnismo como sinônimo de Politecnia, ainda que haja prematuramente um debate acerca de possíveis diferenças, conforme mencionado por Grein (2013).

${ }^{8} \mathrm{Na}$ obra, o autor cita alguns exemplos realizados por escolas russas no período revolucionário: a escola coloca marcos quilométricos; a escola luta contra o fabrico de aguardente caseiro; os estudantes secretariam a reunião dos camponeses; a escola luta contra incêndios; a escola faz campanha para a reconstrução das pontes; a escola luta pela introdução de práticas de higiene; a escola organiza um jardim de infância; a escola organiza uma cooperativa; a escola trabalha na agricultura; a escola eletrifica a aldeia; a escola ajuda o camponês a organizar a contabilidade.
}

TrabalhoNecessário - www.uff.br/trabalhonecessario; Ano 13, № 21/2015. 


\section{Trabalhonecessário}

Issn: $1808-799 X$

ano 13, número $21-2015$

Trabalho Socialmente Necessário feito pela escola, em conjunto com outras forças sociais, é construto advindo de estudos prévios sobre as condições socioeconômicas da comunidade e, consequentemente, a realização prática das ações necessárias que ajudarão na melhoria das condições de vida do lugar:

O essencial consiste em que a escola faça realmente um trabalho socialmente necessário, 0 essencial consiste em que 0 conhecimento que a escola dá, que é necessário, seja realmente útil nestas condições; o essencial é que a expansão e aprofundamento destes conhecimentos sejam ditados não apenas por considerações abstratas, mas pela prática real; consiste em que os conhecimentos sejam imediatamente convertidos em prática, definindo-se, concretizando-se; o fato é que uma, um pedaço de vida empurra para o estudo do todo, que é o dado é estudado ao longo do tempo, em mudança, no movimento, em contradições (p. 67).

É possível afirmar, então, que a razão de ser da escola, no contexto revolucionário específico da Rússia, consistia na prática dos conhecimentos, traduzindo-os em melhoria de vida da população, nos diversos ramos produtivos. Consistia também em um trabalho que fosse orientado para a melhoria da economia, que buscasse elevar o nível cultural e que pudesse proporcionar resultados produtivos; que possuísse um valor pedagógico eminentemente prático, capaz de formar crianças e jovens como trabalhadores da nova sociedade; que estivesse em conformidade com as potencialidades das crianças e jovens, preservando o seu organismo (p. 90).

O autor não elaborou uma proposta para a organização do trabalho pedagógico, no sentido da organização curricular, pois partia das experiências existentes, como os Complexos Temáticos ${ }^{9}$, formulados por Pistrak, de quem era

\footnotetext{
9 Segundo Felix, Moreira e Santos (2007), os complexos temáticos podem ser entendidos como um tipo de organização do trabalho pedagógico escolar, o currículo, as atividades pedagógicas e as formas como se procede a construção do conhecimento a partir do materialismo histórico e dialético. O objetivo é a produção de conhecimento capaz de ajudar na compreensão radical da realidade, estimulando a auto-organização dos sujeitos envolvidos no processo educativo.
}

TrabalhoNecessário - www.uff.br/trabalhonecessario; Ano 13, № 21/2015. 


\section{Trabalhonecessário}

Issn: $1808-799 X$

ano 13, número $21-2015$

companheiro. Shulgin partiu dessa organização e efetivou suas reflexões acerca dos limites que a educação e a escola russas apresentavam naquele contexto. São limites presentes no trabalho da escola, oriundo da dificuldade para realizar uma educação alicerçada no Trabalho Socialmente Necessário como superação da educação e escolas antigas e suas formas "atrasadas", tanto teóricas como práticas, de trabalhar com o conhecimento e com o próprio trabalho.

A observância dos limites educacionais inerentes ao processo revolucionário obrigou Shulgin a destacar que a escola precisa trabalhar coletivamente com outras organizações ${ }^{10}$, justamente porque não poderia resolver os problemas sociais existentes, ainda que fosse uma instituição importante para ajudar a solucioná-los. Em função disso, afirmou que a escola precisaria conhecer o lugar onde está, bem como o papel que esse lugar ocupa no desenvolvimento econômico da região e do país (p. 100). Disso decorre a reflexão do autor sobre a escola como ajudante na resolução de problemas e, por isso, deveria verificar constantemente o que pode fazer para ajudar as outras organizações sociais. Significa que a escola, como uma instituição social importante naquele contexto, deveria responsabilizar-se pela elevação do conhecimento da comunidade, por meio do trabalho educativo e do Trabalho Socialmente Necessário, sistematizando as demandas, contribuindo para aquilo que precisaria ser feito e, principalmente, incorporando nos estudos e na produção de conhecimentos as necessidades apresentadas como limites na vida da comunidade. Para o autor, o conhecimento trabalhado na escola é externo a ela e só pode ser apanhado na medida em que há uma direta relação entre escola e comunidade.

Além desses aspectos, é possível dizer, segundo o autor, que o papel da educação escolar nos primeiros anos da Revolução Russa pode ser visto como

10 Entre as organizações mencionadas por Shulgin, destaca-se o Komsomol que, à época, correspondia à organização (União) da Juventude Socialista e cumpria um papel importante na mediação e formação da juventude revolucionária.

TrabalhoNecessário - www.uff.br/trabalhonecessario; Ano 13, № 21/2015. 


\section{Trabalhonecessário}

Issn: $1808-799 X$

ano 13, número $21-2015$

uma saída para a superação do espontaneísmo, isto é, um conhecimento isolado, desarticulado da situação social, restrito às contingências. Enquanto nível espontâneo, o autor o considerava como um momento importante dos estudos e da produção de conhecimentos, mas insuficiente para a formação de crianças $e$ jovens lutadores e construtores da sociedade comunista. Para tal, seria necessária a organização pedagógica a partir do Trabalho Socialmente Necessário que, uma vez identificado pela escola, precisaria ser feito em conjunto com outras organizações sociais e, daí, emergiriam as temáticas a serem estudadas. Disso, também, entendia o autor que uma escola com tais características não comportaria, em sua estrutura organizativa, o mesmo modelo utilizado antes da Revolução e mesmo aquele baseado na estratificação social, alinhado à divisão social do trabalho. Para Shulgin, a auto-organização era condição importante para que a escola cumprisse suas funções sociais a partir de dentro, sobretudo para a formação de sujeitos coletivos:

O Trabalho Socialmente Necessário requer não apenas conhecimentos e habilidades, não só treino, mas também uma organização específica ou auto-organização das crianças. Sem isso, ele não é viável, é impensável. Da parte das crianças, ele exige capacidade de ação, engenhosidade, desenvoltura, capacidade de observação, interesse, trabalho inteligente; e não o individual, mas o coletivo, não só no seu canto, mas com o povo, na rua, etc. Exige, portanto, a organização. $E$ isso é muito importante. É muito necessário (p. 113).

Nesse sentido, a finalidade da auto-organização não guarda objetivo em si mesma, mas atende à necessidade de um trabalho que precisa ser realizado e, sobretudo, precisa ser compreendido para ser feito. Não se trata do cumprimento de tarefas previamente planejadas por educadores para que outros executassem, mas da criação de um plano de trabalho construído coletivamente, no qual se encontrariam os objetivos a serem alcançados pelo coletivo. Para Shulgin, 0 trabalho a ser realizado deveria seguir basicamente cinco etapas: "1) Trabalho

TrabalhoNecessário - www.uff.br/trabalhonecessario; Ano 13, № 21/2015. 


\section{Trabalhonecessário}

Issn: $1808-799 X$

ano 13, número $21-2015$

planejado, o plano. 2) Propaganda entre a população. 3) Preparação para a sua realização (habilidades, conhecimentos adicionais, aquisição de equipamento, etc.). 4) O próprio ato da execução. 5) Avaliação" (p. 151).

Pode-se perceber que os elementos destacados acima caracterizam a noção sobre o Trabalho Socialmente Necessário e do papel da escola, assim como a relação trabalho/educação. Isso porque diz respeito ao sentido da educação escolar em uma sociedade que precisava ser reconstruída, tanto em seus aspectos materiais e físicos quanto no sentido das novas relações sociais. Por isso também a vigilância de Shulgin em relação ao trato com a educação escolar foi muito importante, pois pode ser interpretada como contribuição a um efetivo processo educativo fundamentalmente orgânico ao todo social que se desenvolvia no país. Uma atenção epistemológica, capaz de identificar os problemas cotidianos da escola russa e produzir conhecimentos sobre, propondo alternativas com base no projeto de sociedade em curso, mas, também, atento ao avanço que a educação necessitava a partir do desenvolvimento socioeconômico que a Rússia alcançava com o passar do tempo.

\section{Do trabalho Socialmente Necessário ao Politecnismo}

Shulgin, consciente de que o processo educativo tinha sua manifestação mais geral a partir do Trabalho Socialmente Necessário, mas que precisava de avanços, inclusive para superar a fragmentação que ainda existia na construção dos conhecimentos e das habilidades necessárias para a nova sociedade, sinaliza o Politecnismo como recusa de uma forma imediata de conhecimento. Para ele,

a experiência dos estudantes é grande, a influência educativa de um processo informal é contínua, e os estudantes vêm para a escola não somente com uma série de habilidades isoladas, 


\section{Trabalhonecessário}

Issn: $1808-799 X$

ano 13, número $21-2015$

conhecimentos, mas também com avaliações, julgamentos, com embriões de programas políticos [...] E muitas vezes acontece que a educação política é educação política e vida é vida separadamente (p. 173).

Para o autor, o Politecnismo elevaria o simples conhecimento a partir do Trabalho Socialmente Necessário e das experiências de vida a uma condição científica, ou seja, um conhecimento elaborado intencional e racionalmente. Aqui, também, a escola tem um papel preponderante: "ajudar as crianças a reconhecer e aprofundar a experiência que elas têm e, além disso, expandi-la intencionalmente com a educação formal" (p. 173). Em Shulgin, tal expansão só é praticável na medida em que as velhas formas utilizadas para produção da vida material forem gradativamente substituídas por outras, modernas, onde a fábrica cumpriria uma função determinante para consolidação da escola politécnica.

A escola politécnica nasce na fábrica. E não é gerada por fantasias ociosas e invenções; ela, sem dúvida, é a continuação do processo educativo não organizado. Mas se ele, informal, ensina de modo espontâneo, caso a caso, e por isso de modo lento e nem sempre correto, ela, organizada, é uma tentativa de compreender esta experiência, usá-la para melhorar o efeito do trabalho. Assim é realmente uma autêntica escola do trabalho, aquele novo tipo de escola que nós seguimos (p. 176).

Ao considerar a fábrica como espaço genuíno da escola politécnica, Shulgin acenou que a educação russa deveria impulsionar, por meio do Politecnismo, outras tecnologias - no sentido da produção social da ciência - que estejam a serviço da sociedade autogerida pelos trabalhadores ${ }^{11}$. Dizia ele "que

11 Para Shulgin, o desenvolvimento russo deveria acarretar na superação da dicotomia entre campo e cidade, e a Politecnia, enquanto um "sistema inteiro" (p. 227), tinha um papel fundamental nesse processo. $O$ autor entende que a formação politécnica requer o conhecimento de todas as frentes de produção e que isso é possível, inevitavelmente, pelo contato com as formas mais desenvolvidas da tecnologia, de modo que possa ser utilizada para a melhoria da produção em todos os ramos. Diz Shulgin: "As crianças dessas cidades vão trabalhar nas fábricas, e no verão, no outono e na primavera, no campo. Assim será. Não está longe. Isso tornar-se-á uma realidade dentro de um ou dois anos. Mas, agora, vemos já as primeiras aproximações, as 


\section{Trabalhonecessário}

Issn: $1808-799 X$

ano 13, número $21-2015$

não se pode mais ser analfabeto, não se pode fazer o trabalho como os antepassados" (p. 180). Ainda sobre isso, o autor russo escreve que

quando, na aldeia, o trabalho é antigo, devemos combatê-lo, rompê-lo, introduzir o novo; e eles, os trabalhadores camponeses, são os melhores propagandistas - agitadores, mas o trabalho é antigo, a tecnologia é antiquada, e não há requisitos suficientes para o Politecnismo (p. 181).

O autor entendia que é na fábrica, lugar onde o conhecimento mais complexificado existe e pode ser produzido, que o Politecnismo tem seu pleno desenvolvimento. Para ele, o trabalho na fábrica não será apenas um espaço para produção de bens, mas "junto com a escola, se tornará um laboratório onde, acima de tudo, o homem da sociedade comunista será valorizado" (p. 188). Isso seria possível porque a fábrica representa o que há de mais organizado, racional e científico - ela representa a superação do antigo modo de produzir a vida.

Indo de um tipo ao outro, do trabalho da fábrica para o trabalho no campo, a criança vai conhecer o básico da produção, adquirir as habilidades necessárias, E esta diversidade de experiência, de observação, de estudo, não caótica, mas organizada em um sistema, não irregular, mas única, não separada em pedaços e no tempo, vai criar um novo homem. Disso falava os fundadores do socialismo científico. Disso falava Lenin (p. 188).

As múltiplas dimensões proporcionadas em uma educação politécnica, conforme acima mencionadas, eram, para Shulgin, uma necessidade diante do rápido processo de industrialização pelo qual a Rússia se encontrava. Decorrente

primeiras realizações neste caminho. São equipes de trabalhadores na aldeia. Elas foram enviadas a centenas de milhares de quilômetros de distância, no próprio coração das aldeias. E lá dirigem o novo: colocam a aldeia mais perto da máquina, um camponês mais perto da cidade; é um ritmo novo, são novas técnicas. Introduzem uma nova organização... Mas ao mesmo tempo, esse trabalho amplia horizonte dos lideres das equipes e os enriquece, o trabalho fabril é substituído por um trabalho no campo, mas um trabalho com máquinas; e esse último novamente cede o seu lugar, em alguns meses, ao trabalho fabril" (p. 223).

TrabalhoNecessário - www.uff.br/trabalhonecessario; Ano 13, № 21/2015. 


\section{Trabalhonecessário}

Issn: $1808-799 X$

ano 13, número $21-2015$

da Nova Política Econômica - NEP e dos esforços revolucionários, o crescimento da indústria exigia a formação profissional em ritmo acelerado, o que acabou por retomar o debate em torno da Politecnia que, passados anos da revolução, ainda não estava consolidado.

\section{Conclusões}

Em síntese, a partir dos estudos de Shulgin, é possível esboçar um entendimento sobre o seu conceito central. Por Politecnia entende-se a práxis educativa, cuja base é o Trabalho em seu sentido ontológico, que consiste na atividade humana fundante dos seres humanos e, consequentemente, da realidade social. Dele partem os conteúdos para o aprendizado teórico-prático de diversas técnicas atreladas ao conhecimento amplo do processo de trabalho e o conhecimento humano em geral, incluindo o avanço nas ciências. É destinada à totalidade da vida escolar e possível em uma escola única (unitária), onde ocorra a formação omnilateral, organicamente articulada a um projeto de emancipação humana e, por isso, não capitalista e nem imperialista.

Desse modo, considerando as características radicais atribuídas à Politecnia por Shulgin, poder-se-ia entender que ela - a Politecnia - é uma mera abstração do pensamento e que as condições para a sua realização são impossíveis, sobretudo em uma sociedade capitalista, e, de forma plena, efetivamente são. Vejamos, como exemplo, a complexidade em que se apresenta à materialização dessa perspectiva no elucidativo caso brasileiro, sobretudo pela força da influência dos interesses empresariais nas políticas educacionais.

Com base nas análises de Leher (2012; 2014) destacamos, resumidamente, três importantes momentos da recente história, nos quais as políticas assumiram contornos específicos, sobretudo pela intensidade da 


\section{Trabalhonecessário}

Issn: $1808-799 X$

ano 13, número $21-2015$

correlação de forças em cada momento. O primeiro foi o período em que predominou a ditadura civil-militar, coincidiu com a ascensão das teses do capital humano, as quais foram deliberadamente assumidas nas políticas públicas e traduzidas em orientações que modificaram a estrutura da educação brasileira, com o fim de colocar a formação escolar/universitária a serviço das orientações demandadas pela aceleração industrial ${ }^{12}$.

O segundo, com o processo que culminou na redemocratização do país e a nova constituição federal, onde houve, em certa medida, uma participação popular ampliada e massiva nos debates em torno do direcionamento que o país deveria assumir. Naquele contexto, o tema da escola unitária e politécnica, somada às duras críticas à orientação pedagógica do capital humano, não chegou a incidir diretamente na política educacional, mas deixou um importante legado, inclusive a existência de fóruns de debates, associações de professores e outras organizações que até hoje são fundamentais para pensar os caminhos das políticas educativas do país.

O terceiro corresponde à crise das lutas sociais e da própria teoria críticosocialista, devido à ofensiva do capital, que se caracteriza por dois movimentos: 1) ligado à introdução das teorias do fim do trabalho e à emergência de temas contingentes, a partir das identidades de gênero, etnia, sem necessariamente uma orgânica relação com a situação de classe; 2) a reafirmação das teses do capital humano, sustentadas em documentos produzidos pelo Banco Mundial, onde reafirmava a importância dessa teoria sobre qualquer outra no campo da educação. Esses dois movimentos articulados dão início a uma nova etapa das políticas públicas brasileiras, marcada pela inserção lenta e gradual dos interesses dos empresários na orientação das políticas educacionais, sob a

12 Leher (2014) lembra-nos dos acordos da "Aliança para o progresso" (1964), MEC-USAID (19671968) e a Lei no $5692 / 1971$ (LDB).

TrabalhoNecessário - www.uff.br/trabalhonecessario; Ano 13, № 21/2015. 


\section{Trabalhonecessário}

Issn: $1808-799 X$

ano 13, número $21-2015$

justificativa de que a escola pública fracassou na missão formativa. Leher (2014)

explicita o início desse processo:

Em 2001, uma fração importante desses empresários criou um Movimento com o sugestivo nome de "Brasil Competitivo", liderado e organizado por um empresário cuja origem é no Rio Grande do Sul: Jorge Gerdau Johannpeter, do Grupo Gerdau. O que faz esse grupo? Começa a organizar setores empresariais para discutir a suposta falta de qualidade da educação pública. Eles difundem um diagnóstico que não é original, pois já está presente nos documentos de um movimento chamado Programa de Reforma Educativa na América Latina e Caribe - PREALC. Quem financia o PREALC é a Agencia Estadunidense de Desenvolvimento -, a Fundação Ford, o Banco Mundial. Em suma, os grandes intelectuais coletivos do capital. Qual é o diagnóstico que eles fazem da falta de qualidade? Essencialmente eles estão dizendo o seguinte: os educadores fracassaram, a escola publica foi generalizada, mas é uma escola pública 'sem qualidade'. Quem sabe fazer as coisas acontecerem? A resposta é óbvia: os empresários. E estes não podem se omitir diante da falência da escola pública, pois isso poderia custar caro à competitividade do país. (p. 169).

Assim, a influência do empresariado ${ }^{13}$ nas políticas educativas ganha força gradativamente e de forma silenciosa. A continuidade desse processo acarretou, no ano de 2006, na criação do "Movimento Compromisso Todos pela Educação ${ }^{14 ",}$ formado pelas instituições acima citadas. Enquanto organização que

\footnotetext{
${ }^{13}$ Leher (2014) nomina alguns grupos empresariais: Banco Itaú-Unibanco, Bradesco, Santander; os grandes meios de comunicação: Fundação Roberto Marinho, Victor Civita; corporações da indústria editorial; setores metalúrgicos, como a Vale e o próprio Grupo Gerdau; os representantes do agronegócio, como a Monsanto (p. 170)

${ }^{14}$ Esse movimento apresenta-se como organização da sociedade civil e funciona, basicamente, por meio da influência dos seus interesses particulares nas políticas públicas da educação, as quais têm sido generalizadas a toda a sociedade, com objetivo de constituir um consenso em torno de suas demandas. Concretamente, essa relação tornou-se cristalina a partir da criação do Plano de Desenvolvimento da Educação - PDE (2006-2007) pelo governo federal, onde o seu documento-base assume implementar as Metas estabelecidas pelo "Movimento Compromisso Todos pela Educação", forjadas a partir dos índices de avaliação internos e externos que são adotados pelo governo. Isso é possível devido ao trânsito livre que os membros dessa organização têm entre as instituições do Estado (p. 171 - 172). Outra forma encontrada pelo
}

TrabalhoNecessário - www.uff.br/trabalhonecessario; Ano 13, № 21/2015. 


\section{Trabalhonecessário}

Issn: $1808-799 X$

ano 13, número $21-2015$

reúne uma fração poderosa da classe dominante, esse movimento exerce influência sobre os mecanismos de decisão que orientam a elaboração das políticas públicas educativas.

Além da constante intervenção dos interesses empresariais nas políticas, convivemos com o incremento da lógica do mercado nas relações que constituem o todo do processo educativo mobilizados pelas políticas públicas, inclusive nos instrumentos democráticos que contam com a participação do povo, como é o caso do Plano Nacional de Educação. Para Leher (2014), nunca vivemos tal situação na educação pública, pois "a cultura das metas, de bater metas, torna-se política de governo e, mais que isso, entra na lei para ser duradoura". (p. 174).

No âmbito da escola, o direcionamento das políticas educativas tem resultado em uma clara fragmentação do conhecimento e do currículo, a descaracterização da escola enquanto lugar de construção do conhecimento, a transformação dos profissionais da educação em gestores de projetos pontuais, as condições materiais dos professores que são suficientes somente a sua própria reprodução. Diante disso, organizar uma pauta em torno do debate sobre os caminhos da educação pública brasileira, o papel do professor, do conhecimento, todas são demandas que residem em um plano secundário, pois se torna abstrato e sem importância, diante do acúmulo de tarefas que conformam o cotidiano das escolas.

Mas por outro lado, os limites que obstaculizam a existência de relações sociais e educativas anticapitalistas e, consequentemente, a Politecnia também apresentam os seus próprios limites, por meio dos quais, não controlam a totalidade da vida social e as possibilidades de superação e práticas não capitalistas. As experiências de resistências, como expressão da luta de classes,

movimento para influenciar os caminhos das políticas educativas é por meio das Organizações da Sociedade Civil de Interesse Público (OSCIP), as quais são representantes dos empresários na relação direta através das políticas de Estado e dos governos.

TrabalhoNecessário - www.uff.br/trabalhonecessario; Ano 13, № 21/2015. 


\section{Trabalhonecessário}

Issn: $1808-799 X$

ano 13, número $21-2015$

são uma realidade. Como exemplo, podem ser citadas as experiências educativas de escolarização desenvolvidas pelo Movimento dos Trabalhadores Rurais Sem Terra - MST. Nelas, há um esforço, ainda que permeado de contradições e dificuldades de toda a ordem, de concretização do trabalho enquanto princípio educativo, de articulação da escola com a comunidade e as lutas sociais específicas dos povos do campo, com a auto-organização dos estudantes, os diferentes tempos escolares, com a atualidade e há, também, a formulação coletiva de plano de estudos e os processos avaliativos.

Obviamente, o conceito de Politecnia desenvolvido por Shulgin é radical. E ele é radical porque se funda no trabalho como a atividade prática, o principal aspecto dinamizador, embora não único, tanto da forma quanto do conteúdo escolar. Da mesma forma, a transposição mecânica para os dias atuais, notadamente na escola pública, e em condições largamente distintas seria um estreito e, talvez, frustrado esforço de entendimento, principalmente mediante ao quadro da transição das políticas resumidamente acima exposto. No entanto, segundo a compreensão dos autores do presente artigo, a relação trabalho/educação coloca a exigência de sermos radicais, ou seja, considerar os aspectos histórico-práticos da experiência revolucionária sem abnegar os limites estruturais, bem como as possibilidades que, em nossa realidade, sobretudo no âmbito da escola e políticas públicas, tal fundamento se torna possível.

Neste aspecto, cabe-nos a tarefa de sermos audaciosos, não substituindo o trabalho pelo conhecimento dos diferentes ramos produtivos, das ciências, das artes ou das técnicas, como se constata, muitas vezes, no debate atual. Cabenos, isto sim, manter a radicalidade, tanto no que diz respeito às proposições para a escola pública, ainda no Modo de Produção Capitalista, como também nas tentativas do desenvolvimento de experiências onde o trabalho seja central para 0 desenvolvimento das práticas educativas, em que as possibilidades e condições existirem.

TrabalhoNecessário - www.uff.br/trabalhonecessario; Ano 13, № 21/2015. 


\section{Trabalhonecessário}

Issn: $1808-799 X$

ano 13, número $21-2015$

\section{Referências}

CIAVATTA, Maria. O ensino integrado, a politecnia e a educação omnilateral.Por que lutamos? Trabalho \& Educação, Belo Horizonte: UFMG, v. 23, no 1, p. 187205, jan-abr 2014.

FÉLIX, Cláudio Eduardo. MOREIRA, Romilson do Carmo. SANTOS, Cláudio Rodrigues. Pistrak e o sistema do complexo na Escola do Trabalho. Práxis Educativa. Vitoria da Conquista, n. 3, p. 211-230, 2007.

FERRO, Marc. A Revolução Russa de 1917. 2. ed. São Paulo: Perspectiva, 1967. FREITAS, Luiz Carlos de. Prefácio. In: SHULGIN, Viktor Nikholaevich. Rumo ao Politecnismo (artigos e conferencias). São Paulo: Expressão Popular, 2013.

LEHER, Roberto. Um Novo Senhor da educação? A política educacional do Banco Mundial para a periferia do capitalismo. Revista Outubro, $3^{\underline{a}}$ Ed. 2012. p. 19-30.

LEHER, Roberto. Atualidade da Política Pública Educacional e desafios da educação dos trabalhadores. In: PALUDO, Conceição (org.). Campo e Cidade em busca de caminhos comuns. Pelotas: UFPel, 2014, p. 159-178.

MORENO, Nahuel. As Revoluções do Século XX. São Paulo: José Luiz e Rosa Sundermann, 2003.

PISTRAK. Fundamentos da escola do trabalho. São Paulo. 4. ed. São Paulo: Boitempo, 2005.

REIS FILHO, Daniel Aarão. A Revolução Russa 1917-1921. São Paulo: Editora Brasiliense, 1989.

SHULGIN, Viktor Nikholaevich. Rumo ao Politecnismo (artigos e conferencias). São Paulo: Expressão Popular, 2013.

TRAGTENBERG, Mauricio. A Revolução Russa. 2. ed. São Paulo: UNESP, 2007.

Recebido em 10 de agosto de 2015.

Aprovado em 08 de setembro de 2015. 